\title{
Evaluating the Urban Sustainable Development on the Basis of AHP: A Case Study for Riyadh City
}

\author{
Abdulaziz Aldegheishem ${ }^{1}$ \\ ${ }^{1}$ Department of Urban Planning, College of Architecture \& Planning, King Saud University, Kingdom of Saudi \\ Arabia \\ Correspondence: Abdulaziz Aldegheishem, Department of Urban Planning, College of Architecture \& Planning, \\ King Saud University, Kingdom of Saudi Arabia. Tel: 966-1-469-5759. E-mail: aldeghei@ksu.edu.sa
}

$\begin{array}{lc}\text { Received: November 1, } 2013 & \text { Accepted: January 27, } 2014 \quad \text { Online Published: March 12, } 2014 \\ \text { doi:10.5539/jsd.v7n2p113 } & \text { URL: http://dx.doi.org/10.5539/jsd.v7n2p113 }\end{array}$

\begin{abstract}
This study aimed to evaluate the urban sustainable development for Riyadh city on the basis of the analytic hierarchy process (AHP). This process is very important to the future development of the urban areas. In order to achieve this goal, indicators of sustainability were defined according to the urban level; and then categorized into three indexes (level of development, development coordination extent, and development potential). The results indicated that the index of Development potential had the greatest priority in comparison with the other indexes.
\end{abstract}

Keywords: urban sustainable development, analytic hierarchy process AHP, assessment indexes, Riyadh City

\section{Introduction}

Increasingly, the world is becoming an urban area. According to Schell and Ulijaszek (1999) and Alpopi, Manole, \& Colesca (2011), approximately $65 \%$ of the world's population is expected to live in cities by 2025 . Hence, this reflects the importance of the urban sustainable development. Furthermore, the development of social, economic and environmental aspects of urban systems reflects the level of urban sustainable development (Hai-yang, Hai-yang \& fang, 2009; Thinh et al., 2002; Kondyli, 2010). The concept of sustainable development was defined by the World Commission on Environment and Development (WCED) as "development that meets the needs of the present, without compromising the ability of future generations to meet their own needs" (WCED, 1987).

Measuring the sustainability in civilized areas, which are critical engines for practicing the local socioeconomic activities, become an outstanding challenge for the environmental managers and decision-makers (Moussiopoulos et al., 2010; $\mathrm{Li}$ et al., 2009). The idea of sustainable development was formulated in order to meet the growing understanding regarding the several strategic relationships between the different urban processes such as the social and economic development; global, regional and local environmental problems; the increase in population and urbanized built-up areas (Malkina-Pykh, 2002; Alpopi, Manole, \& Colesca, 2011).

The analytic hierarchy process (AHP) has the non-structural advantage as a multi-criteria judgment method, which is actually valid for evaluating the urban sustainable development. The AHP model combines both subjective and objective assessments in the form of combination weight based on ratio scales derived from simple pairwise comparisons. However, this model requires three steps: structuring the hierarchy, conducting pairwise comparisons so as to define priorities, and gathering the priorities related to the decision's alternatives or options (Schoner \& Wedley, 1989; Stam, \& Silva, 2003).

Cities are construction systems restricted by various social, systematic and environmental factors, with countless conflicts and interactions underlying these factors (Ma \& Wang, 1984; Li et al., 2009; Kondyli, 2010). However, the High Commission for the development of Riyadh city, stemming from its strategy that aims to modify the services provided for the Built-up area, has established an integrated coordinating program for providing public services within the municipality of Riyadh. Of course the program aims to provide general services and fill out the existed inefficiencies. In addition, the program aims to define the timeline required for providing the public services within the city alongside with creating a modern database that involves the entire public services in terms of their locations and the owned and planed lands relying on the geographic information systems. This in turn represents a supportive tool for the relevant decision makers (Ministry of Municipal Affairs and Projects, 
2000). Thus, the evaluation of urban sustainable development indicates a very significant clue to the future development of Riyadh City.

\section{Methodology}

This study adopted an analytical, descriptive method by using the analytic hierarchy process (AHP). This was performed through selecting the most adequate index depending on a number of criteria. However, the related literature was reviewed (Hai-yang, Hai-yang \& fang, 2009). Depending on the analytic hierarchy process, the current researcher developed a questionnaire that was introduced to a group of specialists. Then, data were collected and the results were inferred which assisted in concluding the recommendations offered at the end of this study.

\subsection{Participants}

The study was applied to a group of experts, who comprises five specialists, working in the field of urban sustainable development. The study instrument was administered on those specialists in order to verify the index.

\subsection{Analytic Hierarchy Process (AHP)}

The Analytic hierarchy process (AHP) is a method that helps the decision maker in evaluating the complicated problems and issues. Furthermore, this method contributes in identifying numerical values for the objective stimuli related to the given problem through conducting comparisons between the various criteria that affect the problem directly. This method is crucial since it assists the decision makers in observing the continuous interaction between the elements of the complicated problem. However, this in turn assists them in defining the problem's elements and setting its priorities depending on their relevant knowledge and experiences as well as the desired goals (Satty, 1990; Stam, \& Silva, 2003).

In order to perform the analytical hierarchy process, it is necessary to undertake the following steps (Saaty, 2008):

a) Identifying the problem by identifying the goal.

b) Identifying the criteria that affect and influence the problem.

c) Identifying the suggested alternatives or solutions that will be compared and differentiated.

d) Constructing the hierarchical model, including the higher level that represents the desired goal; the middle level that represents criteria; sub-criteria that influence the problem; and the lower level that represents the suggested alternatives and solutions that will be compared and differentiated in order to solve the problem.

e) Collecting data, noting that it is required here to identify the personal judgments of the decision makers, the experienced people and researchers who are familiar with the problem in order to provide solutions for it. This is accomplished by conducting personal interviews or special questionnaires related to the analytical hierarchy.

f) Designing pair-wise comparisons matrix, where elements are compared by two-way method for each trait.

g) The pair-wise comparison starts from the top of the hierarchical model, which represent the, as mentioned before, the highest level in the model (the goal). The beginning is done by comparing the criteria relative to the goal where this comparison follows the pair-wise method by comparing between two criteria for the same goal followed by making a shift toward another two criteria to select the goal. There are three criteria allocated to the problem $(\mathrm{C} 1, \mathrm{C} 2, \mathrm{C} 3)$. The matrix is designed as shown in the Table 1 below.

Table 1. Criteria pair-wise-comparisons matrix

\begin{tabular}{cccc}
\hline Goal & C 1 & C 2 & C 3 \\
\hline C 1 & 1 & $a_{12}$ & $a_{13}$ \\
C 2 & $a_{21}$ & 1 & $a_{23}$ \\
C 3 & $a_{31}$ & $a_{32}$ & 1 \\
\hline
\end{tabular}


h) The elements $(\mathrm{C} 1, \mathrm{C} 2, \mathrm{C} 3)$ in the left column are compared to the elements $(\mathrm{C} 1, \mathrm{C} 2, \mathrm{C} 3)$ in the first row of the matrix. Moreover, it should be noted that these comparisons, as mentioned earlier, are numerically, according to the judgments presented by the respondents to the questionnaire. However, the diagonal line values are always equal to 1 as the comparisons are conducted for the elements by themselves.

i) The rest of the matrix is completed with the inverted value, and in this case, the matrix is called "the contradictory matrix".

j) Calculating the priorities and measuring the consistency (no contradiction). This is done by maintaining a single priority for each activity that is known as Eigenvector, and this can be calculated by getting the sum of the column's elements in each matrix and then dividing each element on the sum of the column. However, calculating the average of each column on the new matrix represents a new matrix called the priority matrix. AHP measures the total consistency for judgments by calculating the consistency ratio that must be $10 \%$ or less to indicate that judgments are somewhat random. Then, they must be reviewed to attain consistency with no contradiction.

k) To calculate the consistency ratio, the following formula is applied: (Stam \& Silva, 2003).

$C . R=C . I / R I$

C.I $=(\lambda \max -\mathrm{n}) /(\mathrm{n}-1)$

Where,

$\mathrm{N}=$ number of the matrix elements.

While $\lambda \max$ is calculated by taking the result of the division (multiplying the contradict matrix by the priority matrix) on the priority matrix.

1) The priorities of the alternatives must be calculated relative to the criteria in order to reach the final solution, and this is done by replicating the steps from 6 to 10, but at the same time comparisons between the alternatives are performing relative to each criterion.

m) Finally, the total priority for each matrix is calculated to reach the final step which is represented by multiplying the criteria- priority matrix by the alternative-priority matrix.

\subsection{The Analytic Hierarchical Process (AHP) Model for This Study}

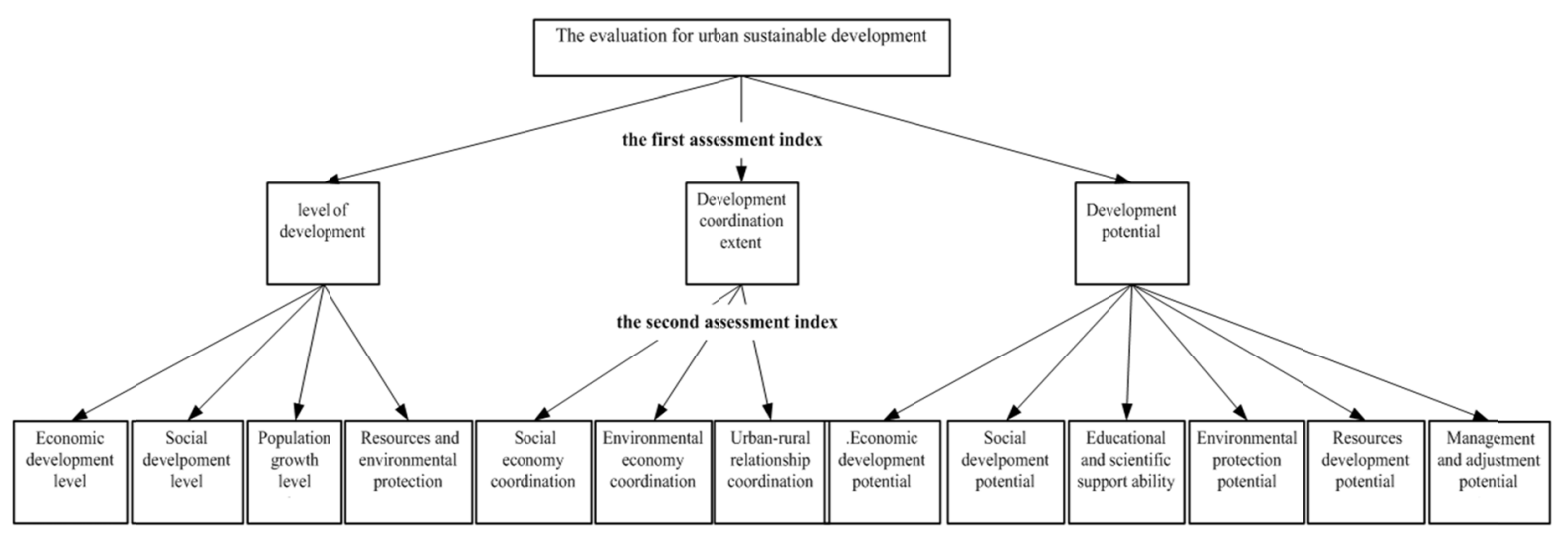

Figure 1. Model of Analytic Hierarchical Process - AHP (Evaluation indexes)

An analytic hierarchical process (AHP) model was constructed in order to evaluate the indexes of urban sustainable development which includes two layers, first and second assessment indexes. The first layer comprises three "first assessment indexes" (level of development, development, coordination extent and development potential). The first assessment index, level of development, includes four "second assessment indexes" which are: economic development level, social development level, population growth level, resources and environmental protection. The other "first assessment index", Development coordination extent, includes three "second assessment indexes" which are: social, economic coordination, social development level and urban-rural relationship coordination. The last "first assessment index", Development potential, includes six 
"second assessment indexes" which are: economic development potential, social development potential, educational and scientific support ability, environmental protection potential, resources development potential, management and adjustment potential (Hai-yang, Hai-yang \& fang, 2009; Alpopi, Manole, \& Colesca, 2011). Accordingly, the study instrument was developed, as shown in Figure 1.

\subsection{Instrument}

In order to achieve the goal of the current study, a questionnaire based on the analytic hierarchy process was developed by following the steps below:

a) The most important adopted criteria were defined to evaluate the urban sustainable development, and then they were used to differentiate between the indexes. The most important adopted criteria were defined to be evaluated according to the criteria (index) mentioned in the previous step. These criteria were set based on reviewing the previous literature and early studies related to urban sustainable development (Thinh et al., 2002). The criteria reported in the study by Hai-yang \& fang (2009) were used. These criteria and their descriptions are shown in Table 2.

Table 2. Evaluation indexes of urban sustainable development

\begin{tabular}{ll}
\hline Decision Criteria: & Description Decision alternatives \\
First assessment index & Second assessment index \\
\hline Level of development & Economic development level \\
& Social development level \\
& Population growth level \\
& Resources and environmental protection \\
Development coordination extent & Social economy coordination \\
& Environmental economy coordination \\
& Urban-rural relationship coordination \\
Development potential & Economic development potential \\
& Social development potential \\
& Educational and scientific support ability \\
& Environmental protection potential \\
& Resources development potential \\
& Management and adjustment potential \\
\hline
\end{tabular}

b) Nine-point scale was used for applying the pair-wise comparisons between the criteria from one hand, and between the alternatives from the other hand based on each criterion. Table 3 shows the graduation in the nine levels.

Table 3. Fundamental scale for pair-wise comparisons

\begin{tabular}{lc}
\hline Verbal scale & Numerical Rating \\
\hline Equally important & 1 \\
Equally to moderately & 2 \\
Moderately more important, likely or preferred & 3 \\
Moderately to strongly & 4 \\
Strongly more important, likely or preferred & 5 \\
Strongly to very Strongly & 6 \\
Very strongly more important, likely or preferred & 7 \\
Very strongly to extremely & 8 \\
Extremely more important, likely or preferred & 9 \\
\hline
\end{tabular}


c) The study instrument emerged in its final form and then was administered to the study's participants (the raters) who comprise five persons.

\subsection{The Analytical Procedure:}

The Expert choice statistical software was used. Especially, this software is used for performing the Analytic Hierarchy Process (AHP). By using this software, the following values were calculated:

a) The relative significance for each index compared to the other first index.

b) The relative significance for each index compared to the other second index.

c) Analyzing the sensitivity of the study index.

\section{Results}

\subsection{Pair-Wise Comparison of the Study Criteria (First Assessment Index)}

The Analytic Hierarchy Process was conducted between the entire criteria as shown in Figure 2 which indicates the relative significance of the criteria.

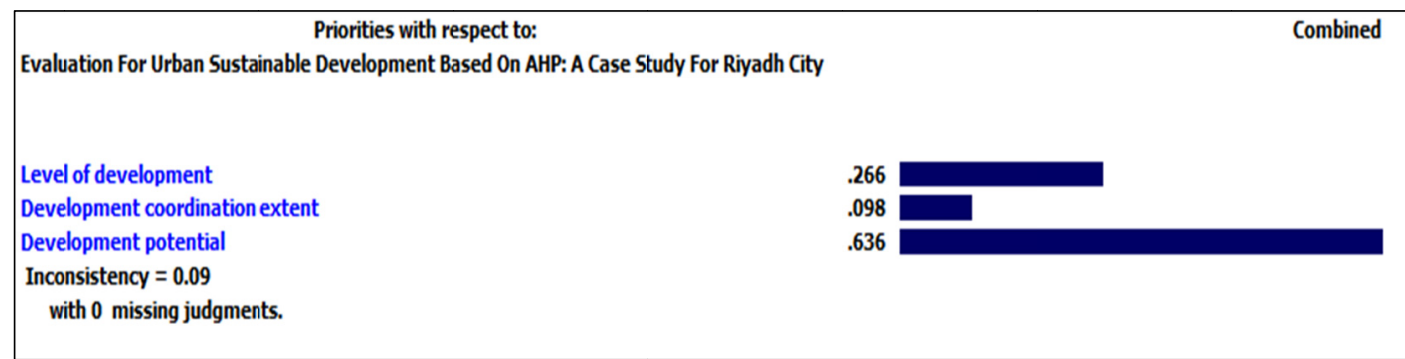

Figure 2. The relative significance of the study's whole criteria related to the first assessment index

The results shown in Figure 2 indicated that the Development potential criterion had the greatest priority, as this criterion reached a relative significance of $63.6 \%$. On the other hand, the reliability coefficient of the judgments of the five experts amounted to 0.09 and regarded as acceptable since it was less than 0.10 , which indicates that the judgments were not random (Saaty, 2008).

The Level of development criterion ranked secondly in terms of the relative significance as compared to the other criteria since its relative significance amounted to $26.6 \%$. The Development coordination criterion came in the final with a relative significance of $9.8 \%$. The following section presents the pair-wise comparisons for each single alternative within the whole alternatives (second assessment index).

\subsection{Pair-Wise Comparisons for Each Alternative for the Whole Study Alternatives (Second Assessment Index)}

\subsubsection{The First Criterion (Level of Development)}

The following figure shows the pair-wise comparisons and the relative significances for the whole alternatives of the study based on the Level of development criterion.

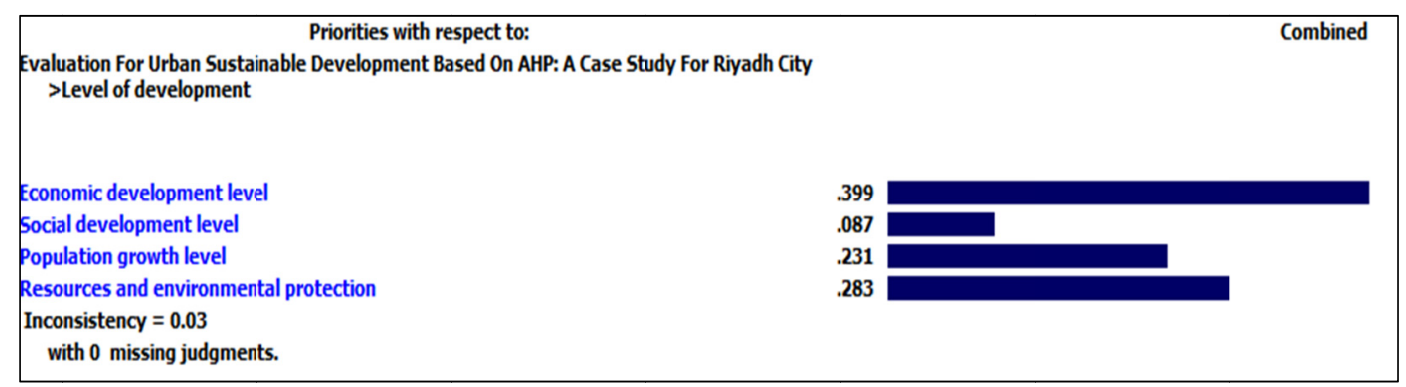

Figure 3. The relative significance for the whole study's alternatives based on the Level of development criterion

Results in Figure 3 indicate that the Economic development level alternative had the greatest priority according to the Level of development criterion since its relative significance amounted to $39.9 \%$. In the other hand, the 
reliability coefficient for the judgments of the five experts amounted to 0.03 , which is regarded as acceptable since it was less than 0.10. This in turn indicates that the judgments were not random.

The Resources and environmental protection alternative as compared to the other was the second alternative with a relative significance of $28.3 \%$, followed by the Population growth level alternative with a relative significance of $23.1 \%$. The Social development level alternative ranked lastly with a relative significance of $8.7 \%$.

\subsubsection{The Second Criterion (Development Coordination Extent)}

Figure 4 shows the pair-wise comparisons and the relative significances for the whole alternatives of the study, according to the Development coordination extent criterion.

\begin{tabular}{|l|l|}
\hline \multicolumn{1}{|c|}{ Priorities with respect to: } \\
Evaluation For Urban Sustanable Development Based On AHP: A Case Study For Riyadh City \\
$>$ Development coordination extent \\
Social economy coordination \\
Environmental economy coordination \\
Urban-rural relationship coordination \\
Inconsistency $=0.09$ \\
$\quad$ with 0 missing judgments.
\end{tabular}

Figure 4. The relative significance for the whole study's alternatives based on the Development coordination extent criterion

Results in Figure 4 indicate that the Social economy coordination alternative had the greatest priority according to the Development coordination extent criterion with a relative significance of $53.4 \%$. In the other hand, the reliability coefficient for the judgments of the five experts amounted to 0.09 , which is regarded acceptable since it was less than 0.10 . This indicates that the judgments were not random.

The second alternative was the environmental economy coordination with a relative significance of $29.9 \%$. The Urban-rural relationship coordination alternative came in the final with a relative significance of $16.7 \%$.

\subsubsection{The Third Criterion (Development Potential)}

Figure 5 shows the pair-wise comparisons and the relative significances for the whole study alternatives, according to the Development potential alternative.

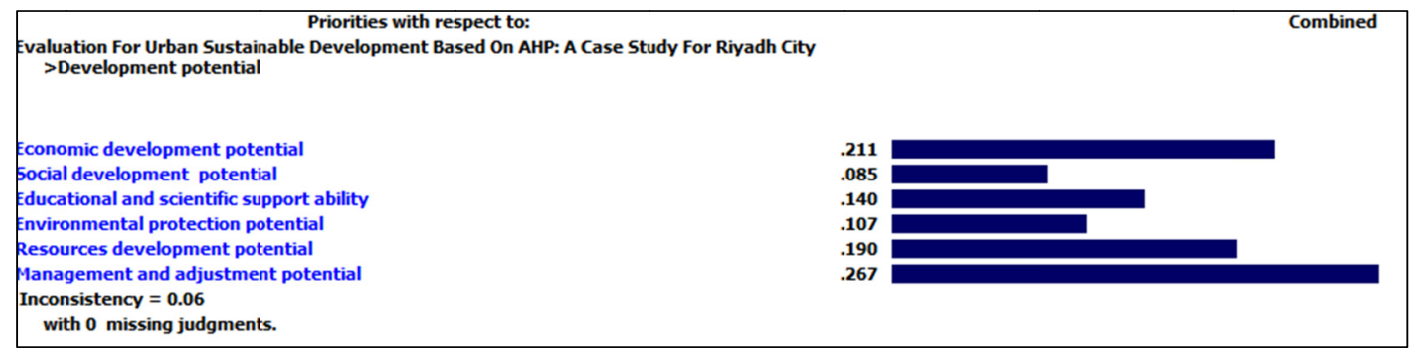

Figure 5. The relative significance for the whole study's alternatives based on the Development potential criterion

Results in Figure 5 revealed that the Management and adjustment potential alternative had the greatest priority according to the Development potential criterion with a relative significance of $26.7 \%$. The reliability coefficient for the judgments of the five experts amounted to 0.06 , which is regarded acceptable since it was less than 0.10 . This indicates that the judgments were not random.

The second alternative was the Economic development potential alternative with a relative significance of $21.1 \%$ as compared to the other alternatives. The third alternative was the Resources development potential with a relative significance of $19 \%$, followed by the Educational and scientific support ability alternative with a relative significance of $14 \%$, then came the Environmental protection potential alternative with a relative significance of $10.7 \%$. The Social development potential alternative came at last with a relative significance of $8.5 \%$. 


\section{Conclusion}

The results indicated that the Development potential criterion had the greatest priority since its relative significance amounted to $63.6 \%$. The Level development criterion came in the second rank in terms of the relative significance as compared to the other criteria while the Development coordination criterion ranked lastly.

The results indicated that the Economic development level alternative had the greatest priority according to level of development criterion. The Resources and environmental protection as compared to the other was the second alternative followed by the Population growth level alternative while the Social development level alternative ranked lastly.

The results indicated that the Social economy coordination alternative had the greatest priority according to the Development coordination extent criterion. The second alternative was the Environmental, economic coordination followed by the Urban-rural relationship coordination alternative which ranked lastly.

The results indicated that the Management and adjustment potential alternative had the greatest priority according to the Development potential criterion. The second alternative was the Economic development potential. The third alternative was the Resources development potential followed by the Education and scientific support ability and the Environmental protection potentials alternatives respectively; while the Social development potential alternative ranked lastly.

In light of the results revealed in this study, the researcher recommends the following:

a. Using the AHP model for evaluating the urban sustainable development since it has a special advantage as a multi-criteria evaluation method as well as it is very suitable for evaluating Riyadh urban sustainable development. Moreover, this study proposes the Development potential index with a greater priority for evaluating Riyadh urban sustainable development.

b. Conducting more similar studies with using more indexes to enhance the Riyadh urban sustainable development.

c. Enhancing studies that adopt the analytic hierarchy theory because of its importance in improving the effectiveness of the decision-making process, especially in Evaluating the Urban Sustainable Development.

\section{References}

Alpopi, C., Manole, C., \& Colesca, S. E. (2011). Assessment of the Sustainable Urban Development Level through the Use of Indicators of Sustainability. Theoretical and Empirical Researches in Urban Management, $6(2), 78-87$.

Kondyli, Julia. (2010). Measurement and evaluation of sustainable development A composite indicator for the islands of the North Aegean region, Greece. Environmental Impact Assessment Review, 30(6), 347-356. http://dx.doi.org/10.1016/j.eiar.2009.08.006

Li, F., Liu, X. Sh., Hu, D., Wang, R. S., Yang, W. R, Li, D. ... Zh, D. (2009). Measurement indicators and an evaluation approach for assessing urban sustainable development: A case study for China's Jining City. Landscape and Urban Planning, 90(3-4), 134-142. http://dx.doi.org/10.1016/j.landurbplan.2008.10.022

Ma, S. J., \& Wang, R. S. (1984). Social-economic-natural complex ecosystem. Acta Ecol. Sin., 4(1), 1-9. (in Chinese).

Malkina-Pykh, I. G. (2002). Integrated assessment models and response functionmodels: pros and cons for sustainable development indices design. Ecol. Indic., 2(1), 93-108. DOI: http://dx.doi.org/10.1016/S1470-160X(02)00048-1

Ministry of Municipal Affairs and Projects. (2000). Controls and the planning standards, Riyadh: Ministry of Municipal Affairs and projects.

Moussiopoulos, N., Achillas, C., Vlachokostas, C., Spyridi, D., \& Nikolaou, K. (2010). Environmental, social and economic information management for the evaluation of sustainability in urban areas: A system of indicators for Thessaloniki, Greece. Cities, 27(5), 377-384. DOI:10.1016/j.cities.2010.06.001

Saaty, T. L. (1990). An exposition of the AHP in reply to the paper remarks on the analytic hierarchy process. Management Science, 36, 259-268. http://dx.doi.org/10.1287/mnsc.36.3.259

Saaty, T. L. (2008). Decision making with the analytic hierarchy process. Int. J. Services Sciences, 1(1), 83-98. http://dx.doi.org/10.1504/IJSSCI.2008.017590 
Schell, L. M., \& Ulijaszek, S. J. (1999). Urbanism, Health and Human Biology in Industrialized Countries. London: Cambridge University Press. http://dx.doi.org/10.1017/CBO9780511525698

Schoner, B., \& Wedley, W. C. (1989). Ambiguous criteria weights in AHP: Consequences and solutions. Decision Sciences, 20, 462-475. http://dx.doi.org/10.1111/j.1540-5915.1989.tb01561.x

Shang, H. Y., \& Su, F. (2009). Evaluation for Urban Sustainable Development Based on AHP. paper presented to conference Intelligent Information Technology Application Workshops, IITAW '09. Third International, 21-22 Nov. 2009, Print ISBN: 978-1-4244-6420-3

Stam, A., \& Silva, A. P. D. (2003). On multiplicative priority rating methods for the AHP. European Journal of Operational Research, 145, 92-108. http://dx.doi.org/10.1016/S0377-2217(02)00228-X

Thinh, N. X., Gunter, A., Bernd, H., Jorg, H., \& Iris, L. (2002). Evaluation of urban land-use structures with a view to sustainable development. Environmental Impact Assessment Review, 22, 475-492. http://dx.doi.org/10.1016/S0195-9255(02)00023-9

WCED. (1987). Our common future: The report of the World Commission on Environment and Development. Official Records of the General Assembly, Forty-second Session, Supplement No, 25 (A/42/25). Retrieved from http://www.un-documents.net/wced-ocf.htm

\section{Copyrights}

Copyright for this article is retained by the author(s), with first publication rights granted to the journal.

This is an open-access article distributed under the terms and conditions of the Creative Commons Attribution license (http://creativecommons.org/licenses/by/3.0/). 